\title{
Elbow lameness in dogs of six years and older
}

\section{Arthroscopic and imaging findings of medial coronoid disease in 51 dogs}

\author{
K. A. G. Vermote1; A. L. R. Bergenhuyzen"; I. Gielen; H. van Bree'; L. Duchateau²; \\ B. Van Ryssen ${ }^{1}$ \\ ${ }^{1}$ Department of Veterinary Medical Imaging and Small Animal Orthopaedics, Ghent University, Merelbeke, Belgium; \\ ${ }^{2}$ Faculty of Veterinary Medicine, Department of Physiology and Biometry, Ghent University, Merelbeke, Belgium
}

\section{Keywords}

Elbow joint, arthroscopy, medial coronoid process, old dogs

\section{Summary}

Objectives: To report on the frequency and distribution of lesions of the medial coronoid process in dogs of six years of age and older, the affected joints. To compare those lesions seen in 'old' dogs with those seen in 'young' dogs between the ages of five and 18 months. Methods: A retrospective study of dogs sixness and subsequent elbow arthroscopy. The dogs were divided into groups according to the lesions of the medial coronoid process diagnosed during arthroscopic examination and computed tomography (CT). The radiographic degree of osteoarthritis (OA) and arthroscopically diagnosed lesions on the medial humeral condyle are described. and to describe the arthroscopic findings in years-old and older admitted for elbow lame-

Results: In 51 'old' dogs, five types of lesions could be identified on arthroscopy and CT: chondromalacia-like lesions (2\%), fissures $(27.5 \%)$, non-displaced fragments (12\%), displaced fragments $(27.5 \%)$, and erosions within the medial compartment without fragmentation (31\%). A significantly different distribution of lesions was seen in 'young' dogs: fissures $(23 \%)$, non-displaced fragments (45\%), displaced fragments (29\%), and erosions within the medial compartment without fragmentation (3\%). No difference in radiographic degree of $\mathrm{OA}$ was seen between the two groups.

Clinical significance: This study demonstrates the relatively high incidence of medial coronoid disease in dogs older than six years of age, and it highlights one particular problem in 'old' dogs: the complete erosion of the medial compartment.

Correspondence to

Kathelijn Anne G. Vermote, DVM

Ghent University

Department of Veterinary medical imaging and small animal orthopaedics

Salisburrylaan 133

Merelbeke, 9820

Belgium

Phone: +31 2647650

Fax: +31 2647793

E-mail: kathelijn.vermote@ugent.be
Vet Comp Orthop Traumatol 2010; 23: 43-50 doi:10.3415/VCOT-09-03-0032

Received: March 18, 2009

Accepted: June 27, 2009

Pre-published online: December 8, 2009

\section{Introduction}

Elbow dysplasia (ED) is a hereditary developmental problem commonly diagnosed in young large-breed dogs, such as the Bernese Mountain dog, Labrador and Golden Retriever, Rottweiler, and German Shep- herd dog. Elbow dysplasia is a complex of joint disorders, and includes fragmented medial coronoid process (FCP), osteochondritis dissecans of the medial humeral condyle (OCD), ununited anconeal process, and elbow incongruity (1). While FCP is the most common cause of $\mathrm{ED}$, a combi- nation of different ED lesions within the same elbow is possible (2-6).

Different degrees of FCP have been described, including fissures, displaced and non-displaced fragments, and chondromalacia-like lesions (7). Cartilage erosions in the region of the medial coronoid process and the medial aspect of the humeral condyle, in absence of coronoid fragmentation, have been reported $(3,8,9)$. The term 'medial coronoid disease' has been introduced by some authors to cover this variety of lesions $(8,10)$.

In recent years, FCP has been described in adult dogs, and three case reports of FCP in older dogs have been documented (1015). In a series of 263 dogs in which prevalence of FCP was described, $13.7 \%$ of the dogs were older than six years (12). Diagnosis of ED is traditionally made by clinical examination followed by radiographic examination (standard and flexed mediolateral, and a cranio-caudal projection). Radiographic suspicion of FCP is often based on secondary changes: unclear delineation of the medial coronoid process, sclerosis of the ulnar notch, and secondary signs of osteoarthritis (OA) of the elbow $(16,17)$. Computed tomography (CT) and arthroscopy are useful to confirm the diagnosis. Computed tomography allows visualisation of the bony structures of the elbow without superimposition of any of the bones (18-20). Therefore, it has a higher specificity $(84.6 \%)$ and sensitivity $(88.2 \%)$ in detecting FCP than radiography $($ specificity $=100 \%$, sensitivity $=23.5 \%)$ (21). Arthroscopy is considered the gold standard for the evaluation of cartilage and permits direct observation of the lesion (22-24). In addition, probing the lesion during arthroscopy can demonstrate the mobility of a fragment. Arthroscopy and 
Table 1 Description of the arthroscopic and computed tomographic-findings in five groups of lesions of the medial coronoid process. ${ }^{*}$ see Table 2.

\begin{tabular}{|c|c|c|}
\hline Diagnosis & $\begin{array}{l}\text { Arthroscopic findings: } \\
\text { medial coronoid process }\end{array}$ & $\begin{array}{l}\text { Computed tomography } \\
\text { findings: medial coronoid } \\
\text { process }\end{array}$ \\
\hline $\begin{array}{l}\text { Chondromalacia-like } \\
\text { lesions }\end{array}$ & $\begin{array}{l}\text { Irregular, soft or fibrillated cartilage } \\
\text { (Outerbridge grade } 1^{\star} \text { ). } \\
\text { No fissure. }\end{array}$ & No subchondroal fissure \\
\hline Fissure & $\begin{array}{l}\text { Cartilage fissure or irregular, soft or } \\
\text { fibrillated cartillage } \\
\text { (Outerbridge grade }{ }^{\star} \text { ). } \\
\text { No mobile fragment when probing. }\end{array}$ & Non-displaced fragment \\
\hline $\begin{array}{l}\text { Non-displaced } \\
\text { fragment }\end{array}$ & $\begin{array}{l}\text { Complete fissure. } \\
\text { Fragment located at its original } \\
\text { position and mobile when probing. }\end{array}$ & Non-displaced fragment \\
\hline Displaced fragment & Fragment cranially displaced. & Fragment cranially displaced \\
\hline $\begin{array}{l}\text { Medial } \\
\text { compartment } \\
\text { erosions }\end{array}$ & $\begin{array}{l}\text { Erosions of medial coronoid process } \\
\text { (Outerbridge grade } 4^{\star} \text { ). } \\
\text { No fragmentation, except cartilaginous } \\
\text { mini-fragments smaller than } 2 \mathrm{~mm} \text {. }\end{array}$ & $\begin{array}{l}\text { No fragmentation } \\
\text { No subchondral fissure }\end{array}$ \\
\hline
\end{tabular}

CT are complimentary techniques, both of which are necessary for complete assessment of the medial coronoid process (25).

An increasing number of 'old' dogs with medial coronoid disease are being presented at our institution. None of them however were treated for elbow problems at a younger age. In order to evaluate the lesions that cause elbow lameness in 'old' dogs, we studied elbow lesions in dogs six years of age or older. A combination of arthroscopy and CT was used to accurately describe the lesion. The radiographic grading of $\mathrm{OA}$, and the lesions of the medial humeral condyle observed using arthroscopy, were described. The pathological findings in the region of the medial coronoid process and their distribution are compared with lesions diagnosed in 'young' dogs.

\section{Material and methods}

\section{Dogs}

In this retrospective study, the medical records of dogs that were presented at the University of Ghent, Department of Medical Imaging and Small Animal Orthopaedics, from 2003 to 2007 with the complaint of elbow lameness were collected. Two groups of dogs were selected: the 'old' dogs were six years or older, and the 'young' dogs were between five- and 18-months-old. Inclusion criteria for both groups were: 1 ) presenting complaint of elbow lameness caused by medial coronoid disease and subsequent arthroscopic evaluation; 2) complete information on signalment, history, clinical and orthopaedic examination; 3 ) a complete set of diagnostic quality radiographs; 4) diagnostic quality CT scans; and 5) video images of the arthroscopic diagnosis and treatment. Cases with incomplete medical records or any elbow pathology other than medial coronoid disease were excluded. The presence of OCD or elbow incongruity concurrently with medial coronoid disease was allowed. Dogs that had a previous elbow arthrotomy or arthroscopy were excluded. Data collected from the medical records included: signalment, age at admission, diagnostic procedures performed, duration of lameness and time from initial clinical signs to surgery.

\section{Diagnosis}

Radiographs included three projections (a flexed mediolateral, neutral mediolateral and a craniocaudal $\left[15^{\circ}\right.$ pronation] $)$. They were scored for OA using the International
Elbow Working Group (IEWG) guidelines (26).

Every dog included in this study had a CT examination of both elbows prior to arthroscopy. Computed tomography images were performed with a single row detector spiral CTa . All dogs were positioned in left lateral recumbence with the front legs parallel and extended cranially. The head of the dog was pulled back with the neck flexed, to avoid interference. Both elbows were scanned at the same time (18). Contiguous slices, each $1 \mathrm{~mm}$ in thickness, were obtained at the level of the radioulnar joint. Digital images were viewed on a workstation with $\mathrm{E}$ film viewer ${ }^{\mathrm{b}}$. The shape and possible fragmentation of the medial coronoid process were evaluated. Computed tomography was solely used to increase the accuracy of the diagnosis and to detect bilateral lesions.

Arthroscopy was performed with a 2.4 or $1.9 \mathrm{~mm}, 25^{\circ}$ fore-oblique arthroscope $\mathrm{c}^{\mathrm{c}}$ using a standard medial approach (24). Digital still and video images of the arthroscopic procedure in all elbows were taken. Radiographs were evaluated by a Diplomate of the European College of Veterinary Diagnostic Imaging (HvB) and CT -scans were reviewed by a staff radiologist specialised in CT and magnetic resonance imaging (IG). Arthroscopic images were evaluated by a staff surgeon specialised in arthroscopy (BVR).

Arthroscopy was used to assess the cartilage, and CT added information on the subchondral bone. The combination of arthroscopy and CT was considered the gold standard to correctly characterise the medial coronoid process lesions. Medial coronoid disease was identified and classified in five groups: chondromalacia-like lesions, fissures, non-displaced fragments, displaced fragments, and medial compartment erosions ( Table 1) (7). Cartilage lesions of the medial humeral condyle were scored according to the modified Outerbridge classification system ( Table 2) and the presence of OCD lesions was recorded. The lateral coronoid process and lateral

\footnotetext{
a Prospeed, GE Medical Systems, Milwaukee, WI, USA

b Merge Efilm, Merge eMed, Milwaukee, Wis, USA Richard Wolf, Knittlingen, Germany
} 
humeral condyle were evaluated for cartilage damage as well.

In order to describe and compare the lesions that caused elbow lameness, the study was limited to the lame side in both age groups. In case of bilateral lameness the most affected joint was included.

\section{Postoperative care}

An intramuscular injection of a non-steroidal anti-inflammatory drug and an intraarticular injection of bupivacain were given at the end of the procedure. A light-pressure bandage was applied on the elbow. Dogs were released on the same day as the arthroscopic treatment. All dogs were treated with a non-steroidal anti-inflammatory drug for three weeks postoperatively. During this period the dogs were walked slowly on the leash. After six weeks, a follow-up examination was carried out.

\section{Statistical analysis}

Fisher's exact test was used to compare the occurrence of the different arthroscopic diagnoses in 'old' dogs versus 'young' dogs. The Wilcoxon rank-sum test was used to compare $\mathrm{OA}$, and cartilage erosion of the medial humeral condyle between the 'old' and 'young' dogs, within the category of arthroscopic diagnosis. Spearman's rank correlation coefficient $(\rho)$ was calculated to describe the correlation between the radiographic degree of OA and the degree of cartilage erosions. The occurrence of unilateral versus bilateral lesions was assessed with Fisher's exact test using a significance level of 0.05 .

\section{Results}

\section{Dogs}

In the period of 2003 to 2007, 660 dogs were presented for first-time arthroscopic treatment of medial coronoid disease: $49 \%$ were 18 months of age or younger $(\mathrm{n}=$ $324) ; 39 \%$ were between 18 -months and six-years-old; and $12 \%$ (77 of the 660 -dogs) were six years or older (referred

Table 2

Modified Outer-

bridge Scoring

System, used for arthroscopic evaluation of cartilage pathology (33) of the medial humeral condyle.

\begin{tabular}{|c|c|}
\hline $\begin{array}{l}\text { Modified } \\
\text { Outerbridge } \\
\text { score }\end{array}$ & Description of gross cartilage findings \\
\hline 0 & Normal cartilage \\
\hline 1 & Chondromalacia (cartilage with softening and swelling) \\
\hline 2 & $\begin{array}{l}\text { Fibrillation } \\
\text { Superficial erosions with pitting or a 'cobblestone' } \\
\text { appearance } \\
\text { Lesions that do not reach subchondral bone }\end{array}$ \\
\hline 3 & $\begin{array}{l}\text { Deep ulceration that does not reach the subchondral } \\
\text { bone }\end{array}$ \\
\hline 4 & $\begin{array}{l}\text { Full thickness cartilage loss with exposure of the } \\
\text { subchondral bone }\end{array}$ \\
\hline 5 & Eburnated bone \\
\hline
\end{tabular}

to as 'old' dogs in this study). Of these 77 'old' dogs, data of the complete protocol (radiographs, CT and arthroscopic images) were available in 51 cases. As a reference group, we randomly selected 31 dogs with complete protocols out of the 'young' dogs aged between five and 18 months.

The male: female ratio was $1.5: 1$ in the 'old' dogs and 3.4: 1 in the 'young' dogs. Fig. 1 shows the breed distribution of the 'old' and 'young' dogs presented for arthroscopic treatment of medial coronoid disease between 2003-2007.

Duration of lameness in the 'old' dogs was variable: in $16 \%(\mathrm{n}=8)$ lameness was present since puppy hood, in 31\% ( $\mathrm{n}=16)$ for a few years ( $1-5$ years), in $45 \%(n=23)$ for a few months (2-4 months), in 6\% $(\mathrm{n}=3)$ for a few weeks (2-4 weeks), and in $2 \%(n=1)$ duration of lameness was not recorded.

Bilateral lesions were seen on CT in 69\% of the 'old' dogs (35 dogs), versus $83 \%$ of the 'young' dogs (26 dogs) $(p=0.17)$.

\section{Radiographic findings}

Radiographic OA is listed in Tables 3 and 4. The difference between 'young' and 'old'

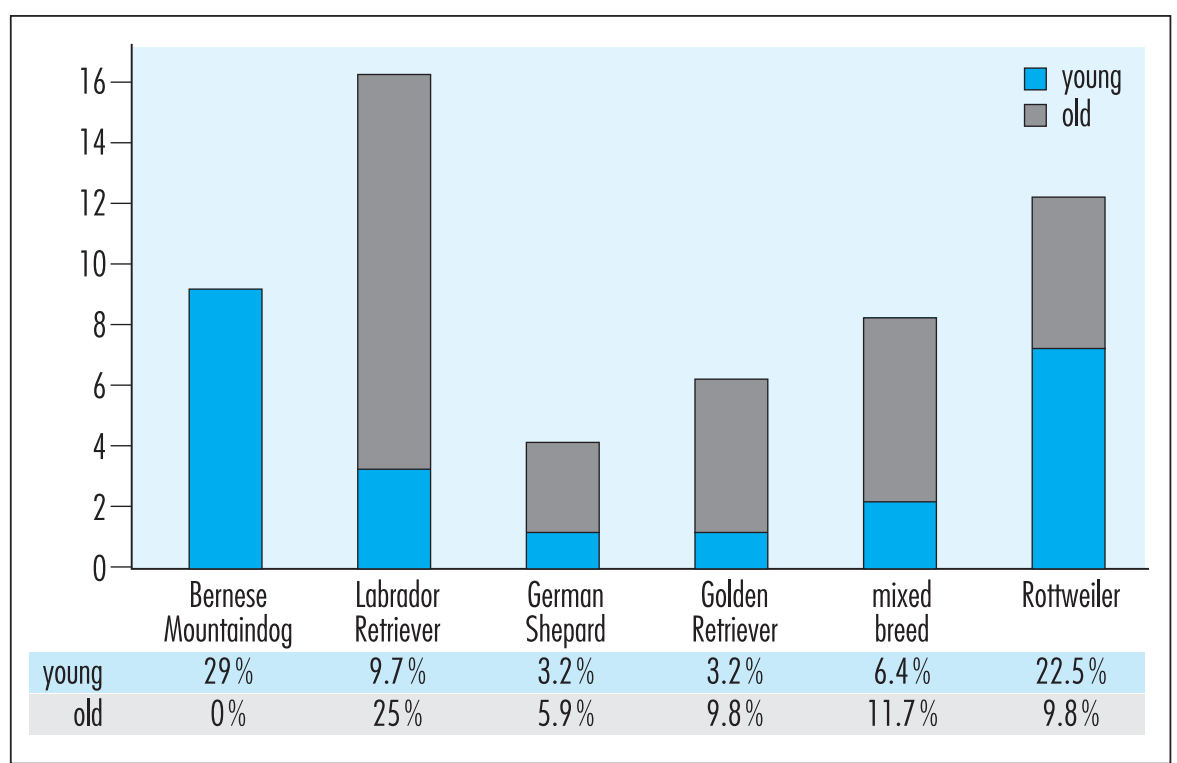

Fig. 1 Breed distribution of 51 'old' dogs and 31 'young' dogs diagnosed with medial coronoid disease between 2003-2007. 
Table 3 Distribution of arthroscopic lesions, and osteoarthritis in 'old' dogs and 'young' dogs.

\begin{tabular}{|l|l|l|l}
\hline & & $\begin{array}{l}\text { Number of 'young' } \\
\text { dogs (\% total) }\end{array}$ & $\begin{array}{l}\text { Number of 'old' dogs } \\
\text { (\% total) }\end{array}$ \\
\hline $\begin{array}{l}\text { Radiographic grade } \\
\text { of osteoarthritis }\end{array}$ & IEWG 0 & $2(6.4 \%)$ & $10(19.6 \%)$ \\
\hline & IEWG 1 & $11(35.5 \%)$ & $8(15.7 \%)$ \\
\hline & IEWG 2 & $13(42 \%)$ & $15(35.3 \%)$ \\
\hline & IEWG 3 & $5(16.1 \%)$ & $18(35.3 \%)$ \\
\hline $\begin{array}{l}\text { Arthroscopic } \\
\text { diagnosis }\end{array}$ & $\begin{array}{l}\text { Chondromalacia-like } \\
\text { lesions }\end{array}$ & 0 & $1(2 \%)$ \\
\hline & Fissure & $7(23 \%)$ & $14(27.5 \%)$ \\
\hline & $\begin{array}{l}\text { Non-displaced } \\
\text { fragment }\end{array}$ & $14(45 \%)$ & $6(12 \%)$ \\
\hline & $\begin{array}{l}\text { Displaced fragment } \\
\text { Medial compartment }\end{array}$ & $9(29 \%)$ & $14(27.5 \%)$ \\
\hline & erosion & $16(31 \%)$ & \\
\hline
\end{tabular}

Key: IEWG: International Elbow Working Group guidelines.

dogs in the degree of $\mathrm{OA}$ was not significant $(\mathrm{p}=0.40)$ (Table 3). Only two $(6.4 \%)$ 'young' dogs did not have any OA, however this was not significantly different from the percentage of 'old' dogs without OA ( $p=$ 0.0915). In both groups, there was a significant correlation between the degree of $\mathrm{OA}$ and the degree of cartilage erosions in the medial compartment $(\rho=0.67 ; p<0.01)$ $(\triangleright$ Table 5). Individual exceptions, however, were seen. Ten 'old' dogs (19.6\%) did not have any OA; six of them belonged to the fissure group, although there was at least one case without $\mathrm{OA}$ in each group of lesions, with the exception of the chondromalacia-like lesions group ( $\triangleright$ Table 4$)$.

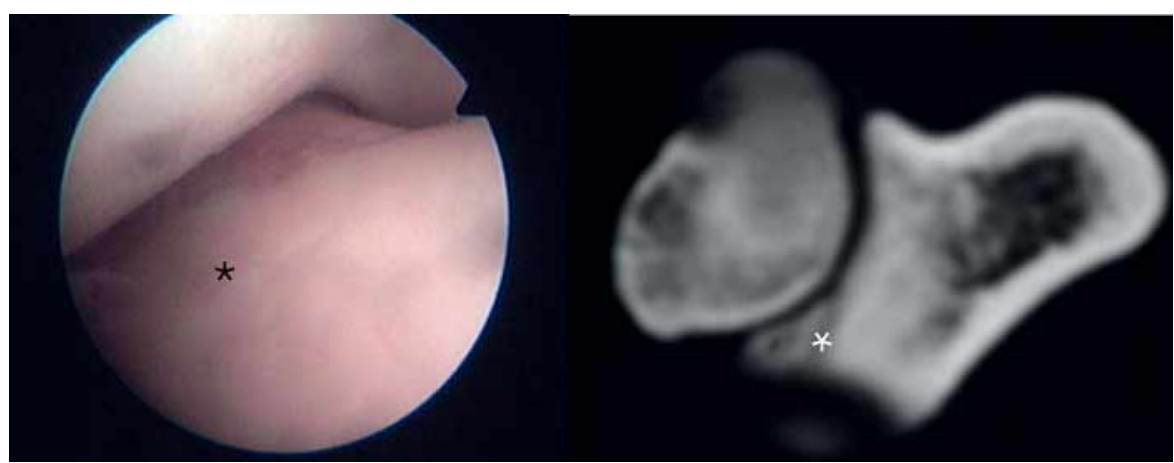

Fig. 2 Fissure in an 'old' dog. Left side: On arthroscopy: irregular, soft and discoloured cartilage without a medial coronoid process fissure $\left({ }^{*}\right)$. Right side: Accompanying computed tomographic image: a subchondral fissure is visible on the medial coronoid process $\left({ }^{*}\right)$

\section{Arthroscopic findings}

Five groups of lesions were identified based on the arthroscopic appearance, combined with the CT findings. The distribution of these lesions in 'old' and 'young' dogs is reported in $>$ Table 3 . The distribution of the lesions was significantly different between the two age classes $(\mathrm{p}=0.0008)$.

Medial compartment erosions were almost exclusively seen in 'old' dogs (31\%) versus (3\%) 'young' dogs. We defined medial compartment erosions as deep ulcerations of the medial part of the joint with exposure of the subchondral bone (Outerbridge classification degree 4), in the absence of fragmentation or fissure formation of the subchondral bone ( $\triangleright$ Fig 3). Articular cartilage of the entire medial humeral condyle was uniformly eroded to the subchondral bone, but the typical wear and tear furrows associated with the displaced fragment cases were not observed. In two cases a very small cartilage fragment $(<2 \mathrm{~mm})$, sandwiched between the radius and ulna, was detected arthroscopically. In two cases (1 'old' dog and 1 'young'), the erosions were restricted to a more limited part of the medial compartment. In all cases of medial compartment erosions, the cartilage of the lateral humeral condyle was grossly normal.

- Table 5 documents the scores of cartilage lesions of the medial humeral condyle, according to the modified Outerbridge classification, in 'old' dogs versus 'young' dogs, in the presence of chondromalacialike lesions, fissures, displaced- and nondisplaced fragments and medial compartment erosions. Kissing lesions (modified Outerbridge degree 4-5) were most frequently seen in the displaced fragment group. In this group significantly more $(\mathrm{p}=$ $0.01)$ kissing lesions were seen in 'old' dogs, and they were also more severe; there were multiple severe wear and tear furrows, surrounded by more superficial erosions, extending over the whole medial aspect of the humeral condyle ( $\triangleright$ Fig 4). In 'young' dogs, displaced fragments were accompanied by more limited kissing lesions (grade 0-4). Concurrent OCD lesions were seen in 16\% of the 'young' dogs, in which case an Outerbridge scoring of the medial humeral condyle was not performed. No OCD flaps were seen in the 'old' dogs ( Table 5). 


\section{Discussion}

This study describes medial coronoid disease in 'old' dogs and compares the findings with lesions in 'young' dogs. The age of the 'young' dogs was chosen based on the etiopathogenesis of FCP as a developmental disease in skeletally immature dogs, and the recommended age for elbow screening given by the IEWG $(2,26-28)$. The age of the 'old' dogs was chosen arbitrarily, and set as high as possible in order to make a clear difference between the findings in 'young' dogs, typically presented for FCP, and the findings in 'old' dogs, for which FCP diagnosis is more unexpected, while still allowing for a sufficient number of cases (29).

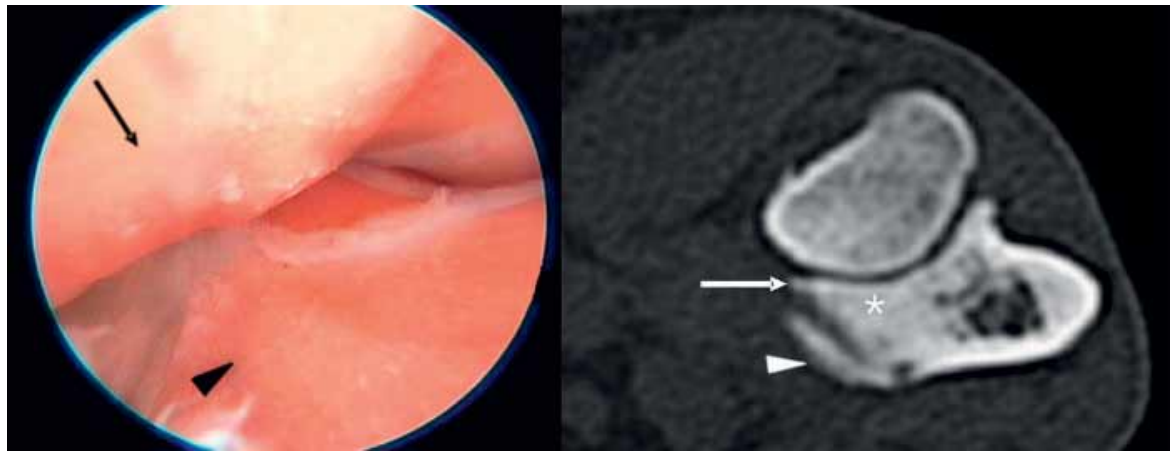

Fig. 3 Medial compartment erosions in an 'old' dog. Left side: Arthroscopic image: Outerbridge grade 4 erosions on the medial humeral condyle (black arrow) and medial coronoid process (black arrowhead). There is no fragmentation. Right side: Accompanying CT image confirms absence of a coronoid fragment and shows a sclerotic medial coronoid process $\left({ }^{*}\right)$. There is a small osteophyte on top of the medial coronoid process (white arrow), a large osteophyte attaches to the medial side of the medial coronoid process (white arrowhead).

Table 4 Arthroscopic findings in elbows with varying radiographic signs of osteoarthritis and classified according to the international elbow working group (IEWG) gradation in 'young' and 'old' dogs.

\begin{tabular}{|l|l|l|l|l|l|l|l|l|l|l|}
\hline $\begin{array}{l}\text { Degree of } \\
\text { osteoarthritis } \\
\text { by IEWG }\end{array}$ & $\begin{array}{l}\text { Chondromalacia-like } \\
\text { lesions }\end{array}$ & Fissure & & $\begin{array}{l}\text { Non-displaced } \\
\text { fragment }\end{array}$ & $\begin{array}{l}\text { Displaced } \\
\text { fragment }\end{array}$ & $\begin{array}{l}\text { Medial } \\
\text { comparment } \\
\text { erosions }\end{array}$ \\
\hline & $\begin{array}{l}\text { Young } \\
\text { dog }\end{array}$ & $\begin{array}{l}\text { Old } \\
\text { dog }\end{array}$ & $\begin{array}{l}\text { Young } \\
\text { dog }\end{array}$ & $\begin{array}{l}\text { Old } \\
\text { dog }\end{array}$ & $\begin{array}{l}\text { Young } \\
\text { dog }\end{array}$ & $\begin{array}{l}\text { Old } \\
\text { dog }\end{array}$ & $\begin{array}{l}\text { Young } \\
\text { dog }\end{array}$ & $\begin{array}{l}\text { Old } \\
\text { dog }\end{array}$ & $\begin{array}{l}\text { Young } \\
\text { dog }\end{array}$ & $\begin{array}{l}\text { Old } \\
\text { dog }\end{array}$ \\
\hline 0 & 0 & 0 & 0 & 6 & 2 & 1 & 0 & 2 & 0 & 1 \\
\hline 1 & 0 & 0 & 5 & 3 & 5 & 4 & 1 & 1 & 0 & 0 \\
\hline 2 & 0 & 1 & 2 & 5 & 7 & 1 & 4 & 3 & 0 & 5 \\
\hline 3 & 0 & 0 & 0 & 0 & 0 & 0 & 4 & 8 & 1 & 10 \\
\hline Total & 0 & 1 & 7 & 14 & 14 & 6 & 9 & 14 & 1 & 16 \\
\hline
\end{tabular}

Key: IEWG - International elbow working group grading scale.

Table 5 The scores of cartilage lesions of the medial part of the humeral condyle according to the modified Outerbridge classification related to the five groups of medial coronoid lesions in 'young' and 'old' dogs .

\begin{tabular}{|c|c|c|c|c|c|c|c|c|c|c|}
\hline \multirow[t]{2}{*}{$\begin{array}{l}\text { Cartilage erosions } \\
\text { medial humeral } \\
\text { condyle }\end{array}$} & \multicolumn{2}{|c|}{$\begin{array}{l}\text { Chondromalacia-like } \\
\text { lesions }\end{array}$} & \multicolumn{2}{|l|}{ Fissure } & \multicolumn{2}{|c|}{$\begin{array}{l}\text { Non-displaced } \\
\text { fragment }\end{array}$} & \multicolumn{2}{|c|}{$\begin{array}{l}\text { Displaced } \\
\text { fragment }\end{array}$} & \multicolumn{2}{|c|}{$\begin{array}{l}\text { Medial } \\
\text { compartment } \\
\text { syndrome }\end{array}$} \\
\hline & $\begin{array}{l}\text { Young } \\
\text { dog }\end{array}$ & $\begin{array}{l}\text { Old } \\
\text { dog }\end{array}$ & $\begin{array}{l}\text { Young } \\
\text { dog }\end{array}$ & $\begin{array}{l}\text { Old } \\
\text { dog }\end{array}$ & $\begin{array}{l}\text { Young } \\
\text { dog }\end{array}$ & $\begin{array}{l}\text { Old } \\
\text { dog }\end{array}$ & $\begin{array}{l}\text { Young } \\
\text { dog }\end{array}$ & $\begin{array}{l}\text { Old } \\
\text { dog }\end{array}$ & $\begin{array}{l}\text { Young } \\
\text { dog }\end{array}$ & $\begin{array}{l}\text { Old } \\
\text { dog }\end{array}$ \\
\hline $\begin{array}{l}\text { Osteochondritis } \\
\text { dissecans }\end{array}$ & 0 & 0 & 1 & 0 & 3 & 0 & 1 & 0 & 0 & 0 \\
\hline 0 & 0 & 1 & 4 & 2 & 4 & 2 & 0 & 0 & 0 & 0 \\
\hline 1 & 0 & 0 & 2 & 7 & 4 & 2 & 1 & 0 & 0 & 0 \\
\hline 2 & 0 & 0 & 0 & 1 & 1 & 1 & 2 & 2 & 0 & 0 \\
\hline 3 & 0 & 0 & 0 & 2 & 1 & 1 & 2 & 1 & 0 & 0 \\
\hline 4 & 0 & 0 & 0 & 2 & 1 & 0 & 3 & 3 & 1 & 16 \\
\hline 5 & 0 & 0 & 0 & 0 & 0 & 0 & 0 & 8 & 0 & 0 \\
\hline Total & 0 & 1 & 7 & 14 & 14 & 6 & 9 & 14 & 1 & 16 \\
\hline
\end{tabular}




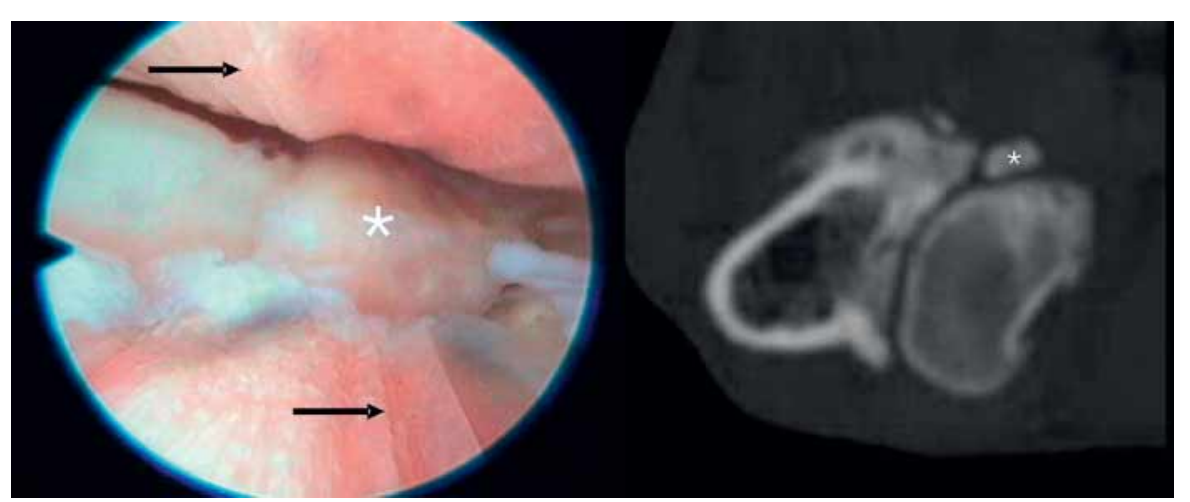

Fig. 4 Cranially displaced fragment in an 'old' dog (*). Left side: Arthroscopic image: Outerbridge grade 5 lesions are seen as racing stripes on the medial humeral condyle and medial coronoid process (arrow head). Right side: Accompanying CT image: the displaced fragment is seen as a separated calcified structure $\left(^{*}\right)$.

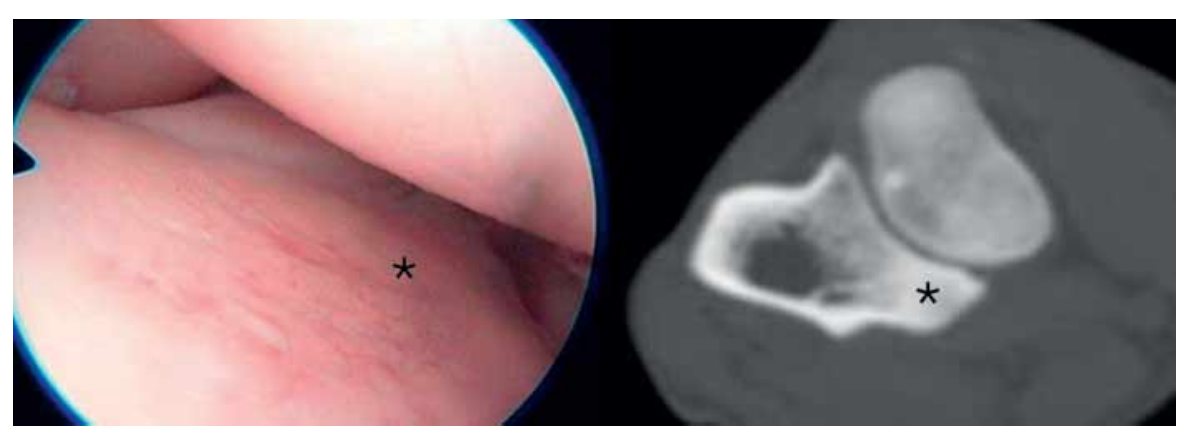

Fig. 5 Chondromalacia-like lesion in an 'old' dog. Left side: On arthroscopy: irregular, soft and discoloured cartilage without afissure of the medial coronoid process $\left({ }^{*}\right)$. Right side:Accompanying computed tomographic image: no sign of fissure formation is visible on the medial coronoid process $\left(^{*}\right)$.

All available 'old' dogs were taken into account, and the 31 randomly selected 'young' dogs were added to arrive at reasonable sample sizes to demonstrate clinically relevant differences.

Although FCP is commonly reported as a developmental disorder affecting young dogs, some reports mention medial coronoid disease in adult and older dogs $(2-4,10$, $30,31)$. The incidence of medial coronoid disease in 'old' dogs in our hospital was $12 \%$, which emphasises the importance of this condition in the differential diagnosis. However, a detailed description of the findings in adult and 'old' dogs has never been published, nor has a comparison been made with lesions found in 'young' dogs to illustrate the difference.

In general, the signalment of 'old' dogs affected with coronoid disease was similar to that of the 'young' dogs concerning bilateral lesions and breed distribution. However there were also differences: the Bernese Mountain dog was not represented in the 'old' group, and mixed breeds were overrepresented in the 'old' group. The Bernese Mountain dog often develops severe elbow changes with fragmentation and incongruity and may therefore show lameness in an earlier age (32). The high number of mixed breeds is unexpected since FCP is considered to be a hereditary disease.

Duration of lameness varied greatly in the 'old' dogs. However, lameness was rarely present since puppy hood, which suggest a later onset of the problem. Read et al mentioned that radiographic evidence of elbow dysplasia is often found without clinical signs (33). The 'old' dogs in our study could have had medial coronoid disease since puppy hood, but without any signs of apparent lameness. This can be supported for a number of dogs in our study by the fact that the medial aspect of the humeral condyle has more severe lesions in 'old' dogs ( $>$ Table 5).

Except for medial compartment syndrome and chondromalacia-like lesions, all lesions were well represented in both age classes. Fissure and displaced fragments appeared equally in both groups, but in the 'old' dogs it was accompanied by a higher degree of cartilage erosions on the medial aspect of the humeral condyle. Although the original cause and time of the development of the disease could not be established exactly, the lesions in 'old' dogs seemed more severe, which may suggest that the lesion has been present for a longer time. On the other hand, some 'old' dogs had lesions that were similar to those in 'young' dogs without any secondary changes.

Medial compartment erosions were typical in 'old' dogs. The only case seen in a 'young' dog affected a more limited area of the medial compartment. Medial compartment erosions have been mentioned in other publications on dogs with FCP, but the incidence of medial compartment erosions in the absence of fragmentation has not been described previously $(3,4,8,9)$. In this study, the absence of a fragment or fissure in the medial coronoid process was assessed on CT and during arthroscopy. In two joints, a mini-fragment (smaller than 2 $\mathrm{mm}$ ) of cartilage was visualised only at the time of arthroscopy. It is the authors' conviction that these mini-fragments were not the cause of the extensive erosions that were observed, and therefore, these joints were not classified as non-displaced fragment cases.

Because medial compartment erosions showed an even wear of the cartilage without any evidence of defect, fissure or fragmentation of the medial coronoid process, the origin of this 'syndrome' cannot be explained by fragmentation of the medial coronoid process and thus cannot be classified as an old eroded FCP lesion. Most likely, the development of medial compartment erosions can be explained by a different progress in pathogenesis than the classical FCP lesions.

Medial compartment erosions may be caused by elbow incongruity (radio-ulnar step or humero-ulnar incongruence) (34). Grading incongruity in clinical cases is a diagnostic challenge and was beyond the aim of this study.

The low number of chondromalacia cases in this study compared to other reports in the literature is due to the design of this study: description of lesions causing 
elbow lameness $(7,35)$. In bilateral cases, the thoracic limb with clinical signs was assessed, excluding the less severe lesions among which chondromalacia lesions were well represented (unpublished data). Another reason for the low number of chondromalacia-like lesion can be explained by the definition used in this study: additional to the arthroscopic diagnosis of irregular cartilage as described in literature, CT findings of the subchondral bone were used to classify the lesion ( Fig 5) $(7,35)$. Therefore, when a subchondral bone fissure was seen on CT and when an Outerbridge grade 1 cartilage was seen during arthroscopy, the lesion was classified as a fissure, and not as chondromalacia-like lesions. Indeed it has been suggested that fragmentation is initiated in the subchondral bone, and progresses into the articular cartilage (36).

In the 'old' dogs, an OCD cartilage flap or focal defect in the articular cartilage and underlying subchondral bone could not be demonstrated, although it cannot be proven that a flap had never been present in an early stage. However, OCD of the elbow, in contrast with FCP, is known to produce clinical signs at a young age (37).

In previous years it has been stated that "if no osteophyte formations are visible radiographically in cases of elbow lameness in dogs over 2 years old, FCP is usually not considered or is even excluded"(38). In more recent literature this has been contradicted $(13,39)$. In this study, $19.6 \%$ of the 'old' dogs had no OA (IEWG grade 0 ). The absence of $\mathrm{OA}$ was most frequently (but not exclusively) seen in the fissure group. In this study, radiographic OA was significantly correlated to the extent of the cartilage erosions. Although there was a clear trend, this does not apply for every individual. The most striking exception to this was the absence of osteophytes in a joint with severe erosions of the complete medial compartment. The same findings, although with low significance have been found in other studies $(4,25)$. Another assumption is that radiographic OA is correlated with age. This study showed a relatively high incidence of 'old' dogs with minimal OA. Thus, the presence of a coronoid lesion in 'old' dogs, even when chronic, is not necessarily associated with severe OA.
In this study the combination of CT and arthroscopy was considered to be the gold standard for classification of the lesion. While arthroscopy is limited to the inspection of the joint surface and may provide limited view due to narrow joint space, CT was useful in the detection of subchondral bone fissures and confirmed the absence or presence of a fragment. In most cases, CT and arthroscopic assessment revealed a similar type of lesion. Arthroscopy did fail to demonstrate a fissure in four cases because the cartilage overlying the subchondral bone fissure appeared intact. The presence of large cracks in the trabecular bone without overt abnormalities in the overlying cartilage, has also been reported in a morphologic study of medial coronoid process (36).

As this was a retrospective study, it had limitations. The population studied was not selected randomly, but was instead selected based on complete files. Thus, these cases do not represent all cases of elbow disease presented at our institution during the study period. It was the purpose of this study to evaluate medial coronoid disease as a cause of lameness in 'old' dogs. At our institution, arthroscopic diagnosis and treatment is routinely performed on both elbows in 'young' dogs with bilateral lesions, even if only unilateral lameness is apparent. In contrast, in 'old' dogs, arthroscopy is often restricted to the clinically affected joint. By comparing both elbows in young dogs, with the lame elbow in old dogs we felt that bias concerning the severity of lesions causing lameness would be introduced. This explains why the lesions of only one elbow were evaluated. One should keep in mind that these data illustrate the distribution of medial coronoid disease in 'old' dogs compared to 'young' dogs. The outcomes were not evaluated in terms of incidence of risk factors when comparing 'old' dogs to all dogs presented at our institution.

\section{Conclusions}

It can be concluded that medial coronoid disease is not confined exclusively to pathology in 'young' dogs. In 'old' dogs, medial coronoid disease is an important differ- ential diagnosis for elbow lameness, with a relatively high incidence. A different distribution of the lesions was seen in the two age groups. Medial compartment erosions (modified Outerbridge grade 4) without macroscopic fragmentation of the medial coronoid process were frequently seen as a typical lesion in 'old' dogs. Further studies are necessary to determine the etiopathogenesis of these erosions and their treatment options.

\section{Reference List}

1. Hazewinkel HAW. Clinical investigation and treatment of elbow problems in the dog. Proceedings of the 14th annual meeting of the International Elbow Working Group; 2003 May 22; Estoril, Portugal.

2. Grondalen J. Arthrosis with special reference to the elbow joint of young rapidly growing dogs. II. Occurrence, clinical and radiographical findings. Nord Vet Med 1979; 31: 69-75.

3. Grondalen J, Grondalen T. Arthrosis in the elbow joint of young rapidly growing dogs. V. A pathoanatomical investigation. Nord Vet Med 1981;33:1-16.

4. Olsson SE. The early diagnosis of fragmented coronoid process and osteochondritis dissecans of the canine elbow joint. J Am Anim Hosp Assoc 1983; 19: 616-626.

5. Wind AP, Packard ME. Elbow incongruity and developmental elbow diseases in the dog .2. J Am Anim Hosp Assoc 1986; 22: 725-730.

6. Meyer-Lindenberg A, Fehr M, Nolte I. Co-existence of ununited anconeal process and fragmented medial coronoid process of the ulna in the dog. J Small Anim Pract 2006; 47: 61-65.

7. Van Ryssen B, Van Bree H. Arthroscopic findings in 100 dogs with elbow lameness. Vet Rec 1997; 140: 360-362.

8. Mason DR, Schulz KS, Fujita Y, et al. Measurement of humeroradial and humeroulnar transarticular joint forces in the canine elbow joint after humeral wedge and humeral slide osteotomies. Vet Surg 2008; 37: 63-70.

9. Schulz KS, Krotscheck U. Canine elbow dysplasia. In: Textbook of Small Animal Surgery (3rd ed.) Douglas Slatter (editor). W. B. Saunders, Philadelphia; 2009: 1927-1952.

10. Fitzpatrick N, Smith TJ, Evans RB, et al. Radiographic and arthroscopic findings in the elbow joints of 263 dogs with medial coronoid disease. Vet Surg 2009; 38: 213-223.

11. Hazewinkel HA. Elbow dysplasia; clinical aspects and screening programs. Proceedings of the $28^{\text {th }}$ World Congress of the World Small Animal Veterinary Association; 2003 Oct 24; Bangkok, Thailand; 2003.

12. Fitzpatrick N, Smith TJ, Evans RB, et al. Subtotal coronoid ostectomy for treatment of medial coronoid disease in 263 dogs. Vet Surg 2009 Feb; 38: 233-245.

13. Meyer-Lindenberg A, Langhann A, Fehr M, et al. Prevalence of fragmented medial coronoid process of the ulna in lame adult dogs. Vet Rec 2002; 151:230-234. 
14. Flo GL. Surgical removal of fragmented coronoid processes and fractured anconeal process in an older dog with evidence of severe degenerative joint disease. J Am Vet Med Assoc 1998; 213:1780-1782.

15. Samoy Y, Van Ryssen B, Van Caelenberg A, et al. An atypical case of fragmented medial coronoid process in a dog. Vlaams Diergeneesk Tijdschr 2005; 74: $154-161$.

16. Henry WB, Jr. Radiographic diagnosis and surgical management of fragmented medial coronoid process in dogs. J Am Vet Med Assoc 1984; 184: 799-805.

17. Lewis DD, Parker RB, Hager DA. Fragmented medial coronoid process of the canine elbow. Compend Contin Educ Veterinarian Pract Vet 1989; 11: 703.

18. De Rycke LM, Gielen IM, van Bree H, et al. Computed tomography of the elbow joint in clinically normal dogs. Am JVet Res 2002 Oct; 63: 1400-1407.

19. Reichle JK, Park RD, Bahr AM. Computed tomographic findings of dogs with cubital joint lameness. Vet Radiol Ultrasound 2000; 41:125-130.

20. Snaps FR, Balligand MH, Saunders JH, et al. Comparison of radiography, magnetic resonance imaging, and surgical findings in dogs with elbow dysplasia. Am J Vet Res 1997; 58: 1367-1370.

21. Carpenter LG, Schwarz PD, Lowry JE, et al. Comparison of radiologic imaging techniques for diagnosis of fragmented medial coronoid process of the cubital joint in dogs. J Am Vet Med Assoc 1993; 203:78-83.

22. Van Ryssen B, Van Bree H, Missinne S. A Survey of 200 Arthroscopies in 150 Dogs and Cats. Vlaams Diergeneesk Tijdschr 1993; 62: 87-94

23. Meyer-Lindenberg A, Langhann A, Fehr M, et al. Arthrotomy versus arthroscopy in the treatment of the fragmented medial coronoid process of the ulna (FCP) in 421 dogs. Vet Comp Orthop Traumatol 2003; 16: 204-210.

24. Van Ryssen B, Van Bree H, Simoens P. Elbow Arthroscopy in Clinically Normal Dogs. Am J Vet Res 1993; 54: 191-198.

25. Moores AP, Benigni L, Lamb CR. Computed tomography versus arthroscopy for detection of canine elbow dysplasia lesions. Vet Surg 2008; 37: 390-398.

26. International Elbow Working Group. Guidelines for radiographic examination and interpretation of the elbow joint. Proceedings of the 2nd Annual Meeting San Francisco, California, USA. 1990 Mar 29; 1990.

27. Fox SM, Roberts RE. Linear tomography in diagnosing fragmented coronoid processes in canine elbows. Compend Contin Educ Veterinarian Pract Vet 1987 Jan; 9: 60-65.

28. Mason TA, Lavelle RB, Skipper SC, et al. Osteochondrosis of the elbow joint in young-dogs. J Small Anim Pract 1980; 21:641-656.

29. Everts RE, Hazewinkel HAW, Rothuizen J, et al. Bone disorders in the dog: A review of modern genetic strategies to find the underlying causes. Vet Q 2000; 22: 63-70.

30. Berzon JL, Quick CB. Fragmented coronoid process - anatomical, clinical, and radiographic considerations with case analyses. J Am Anim Hosp Assoc 1980; 16: 241-251.

31. Boulay JP. Fragmented medial coronoid process of the ulna in the dog. Vet Clin North Am Small Anim Pract 1998; 28: 51-74.

32. Hazewinkel HAW, Ubbink GJ. Elbow dysplasia in the Dutch Bernese Mountain dog population. Pro- ceedings of the International Elbow Working Group; 1999 Jan 8; Orlando, Florida, USA.

33. Read A, Armstrong SJ, Black AP, et al. Relationship between physical signs of elbow dysplasia and radiographic score in growing Rottweilers. J Am Vet Med Assoc 1996; 209: 1427-1430.

34. Fitzpatrick N, Yeadon R, Smith T, et al. Techniques of application and initial clinical experience with sliding humeral osteotomy for treatment of medial compartment disease of the canine elbow. Vet Surg 2009; 38: 261-278.

35. Meyer-Lindenberg A, Heinen V. Therapy and results of chondromalacia like lesions and cartilage abrasions in the canine elbow joint. Proceedings of the 47th BSAVA Congress; 2004 April 1-4; Birmingham, UK.

36. Danielson KC, Fitzpatrick N, Muir P, et al. Histomorphometry of fragmented medial coronoid process in dogs: A comparison of affected and normal coronoid processes. Vet Surg 2006; 35: 501-509.

37. Kirberger RM, Fourie SL. Elbow dysplasia in the dog: pathophysiology, diagnosis and control. J S Afr Vet Assoc 1998; 69: 43-54.

38. Walde I, Tellhelm B. Fragmented medial coronoid process of the ulna (Fcp) and osteochondritisdDissecans (Ocd) of the canine elbow-joint and hock-joint - literature-review, diagnosis and therapy. Wien Tierarztl Monatsschr 1991; 78: 414-424.

39. Punke JP, Hulse DA, Kerwin SC, et al. Arthroscopic documentation of elbow cartilage pathology in dogs with clinical lameness without changes on standard radiographic projections. Vet Surg 2009; 38: 209-212. 